\title{
Recuperação e resposta germinativa de sementes de leguminosas passadas pelo trato digestório bovino
}

\author{
Evandro Afonso Nakao ${ }^{1,2}$ \& Victor José Mendes Cardoso ${ }^{I}$ \\ ${ }^{1}$ Departamento de Botânica, Universidade Estadual Paulista “Júlio de Mesquita Filho” - UNESP \\ Av. 24A, 1515, CEP 13506-900, Rio Claro, SP, Brasil, www.rc.unesp.br \\ ${ }^{2}$ Autor para correspondência: Evandro Afonso Nakao, e-mail: nakaojp@hotmail.com
}

NAKAO, E.A. \& CARDOSO, V.J.M. Recovery and germination of legume seeds passed through the digestive tract of bovine cattle. Biota Neotrop. 10(3): http://www.biotaneotropica.org.br/v10n3/en/ abstract?article+bn03410032010.

\begin{abstract}
Seed germination can be influenced by passage through the digestive system of animals, which can act as seed dispersers, depending on how seeds are affected. When passing through the animal digestive tract does not reduce the seeds germination, the dispersal agent is considered legitimate. The effects of ingestion by bovine cattle (Bos Taurus Linnaeus (1758)) on the viability and germination of seeds of the species Leucaena leucocephala (Lam.) de Wit, Cajanus cajan (L.) Huth and Calopogonium mucunoides Desv. was investigated in this study, aiming at evaluating the role of cattle as legitimate dispersers of those forage plants. Seed samples were mixed with the food offered to three B. taurus females, whose feces were collected 36 hours after ingestion, and seeds recovered from the feces were quantified and tested for germination and initial seedling growth. Noningested seeds were used as a control. The percentage of undamaged seeds recovered ranged from 12.3 to $17.5 \%$. The germination capacity (germinability) of $C$. cajan was strongly inhibited by the cattle ingestion, whereas the germinability of $C$. mucunoides was less affected. The germinability of L. leucephala was not influenced by the ingestion probably due to their hard seed coat. The germination rate of C. mucunoides and L. leucocephala seeds was slightly increased by cattle ingestion, whereas the Emergence Rate Index (ERI) was reduced in the former. The ingestion by cattle also caused a decrease in the growth rate of C. cajan and C. mucunoides seedlings, although this inhibitory effect was smaller in $C$. cajan. The height of L. leucocephala seedlings was increased by ingestion. The results suggest that bovine cattle aren't legitimate seed dispersers of L. leucocephala, C. mucunoides and C. cajan.
\end{abstract}

Keywords: seed dispersal, forage species, Leucaena leucocephala, Calopogonium mucunoides, Cajanus cajan.

NAKAO, E.A. \& CARDOSO, V.J.M. Recuperação e resposta germinativa de sementes de leguminosas passadas pelo trato digestório bovino. Biota Neotrop. 10(3): http://www.biotaneotropica.org.br/v10n3/pt/ abstract?article+bn03410032010.

Resumo: A germinação de sementes pode ser influenciada pela passagem através do trato digestório animal, que, nesse caso, poderá atuar como dispersor, dependendo de como as sementes são afetadas. Quando a passagem pelo trato digestório animal não reduz a capacidade germinativa das sementes, o agente dispersor é considerado legítimo. Este trabalho aborda a influência da ingestão de sementes de Leucaena leucocephala (Lam.) de Wit, Cajanus cajan (L.) Huth e Calopogonium mucunoides Desv. por Bos taurus Linnaeus (1758), sobre sua germinação e viabilidade, com o objetivo de avaliar o gado bovino como legítimo agente dispersor dessas espécies utilizadas como forrageiras. Amostras de sementes foram misturadas ao alimento oferecido a três fêmeas de B. taurus, cujas fezes foram recolhidas até 36 horas após a ingestão e submetidas à triagem para recuperação das sementes, as quais foram testadas para germinação e crescimento inicial. Como controle foram usadas sementes intactas não ingeridas. A porcentagem de recuperação de sementes não danificadas variou de $12,3 \%$ até cerca de $17,5 \%$. A ingestão pelos animais afetou severamente a capacidade de germinação das sementes de Cajanus cajan, enquanto que em Calopogonium mucunoides a redução da porcentagem de germinação ocorreu em menor escala em comparação com a primeira. No caso de L. leucocephala, a germinação não foi influenciada pelo tratamento, o que no caso pode estar relacionado a uma maior dureza do tegumento em sementes dessa espécie. Em C. mucunoides e L. leucocephala a velocidade de protrusão radicular foi ligeiramente aumentada em sementes tratadas, ao passo que o IVE da primeira foi reduzido. A ingestão também reduziu a taxa de crescimento em altura de plântulas de C. cajan, sendo o efeito menos acentuado em C. mucunoides. Em L. leucocephala, a altura média foi maior em plântulas de sementes tratadas. Os resultados sugerem que o gado bovino não pode ser considerado um legítimo dispersor para L. leucocephala, C. mucunoides e C. cajan.

Palavras-chave: dispersão de sementes, forrageiras, Leucaena leucocephala, Calopogonium mucunoides, Cajanus cajan. 


\section{Introdução}

No ambiente natural, além da ação de fatores físicos (como potencial de água e temperatura), a germinação de uma semente pode sofrer a influência de fatores bióticos, como a ingestão por aves ou mamíferos, sendo que nesse caso, o agente biótico pode atuar como dispersor da semente. A dispersão é o transporte da semente para longe da planta mãe. Ela pode trazer benefícios para planta, como ocupar novos ambientes, ou reduzir a mortalidade dependente da densidade por predação, parasitismo ou competição intra-específica (Janzen 1970). Segundo Fleming \& Sosa (1994), dispersores de sementes influenciam o sucesso reprodutivo de plantas em função de sua legitimidade (efeito sobre a capacidade germinativa das sementes dispersadas), eficiência (dispersão em locais apropriados) e efetividade (proporção de plântulas originadas de sementes dispersadas em relação ao total de plântulas estabelecidas). Segundo Figueroa \& Castro (2002), um dispersor é considerado legítimo para determinada espécie quando não causa redução da capacidade germinativa das sementes dispersadas. Entretanto, dispersores não legítimos podem influenciar positivamente o sucesso reprodutivo de uma espécie vegetal desde que possuam alta eficiência de dispersão (Janzen 1984).

Segundo alguns pesquisadores (Janzen 1984, Quinn 1994 et al., Fischer et al. 1996, Malo \& Suarez 1995), grandes herbívoros podem dispersar diásporos de espécies vegetais das quais se alimentam, já que as sementes são ingeridas juntas à folhagem. Em alguns casos, as fezes podem constituir-se num ambiente apropriado para a germinação e crescimento inicial da semente (Gökbulak \& Call 2004). Segundo Gardener (1993), sementes com tegumentos mais duros sobrevivem melhor pela passagem através do trato digestório de bovinos do que sementes "moles", já que o tegumento rígido pode restringir as trocas entre a semente e o meio externo. A passagem da semente pelo trato digestório pode provocar alterações em sua longevidade e dormência, bem como na porcentagem e velocidade de germinação, e crescimento inicial da plântula (Machado et al. 1997). Tais alterações estão relacionadas, entre outros fatores, ao período de retenção no intestino, tamanho da semente, dureza do tegumento e estágio de maturidade dos propágulos (Janzen 1985). Segundo Simão Neto et al. (1987), sementes grandes ou com tegumento totalmente permeável são mais propensas a danos causados pela mastigação, ao passo que sementes menores atravessam o trato digestório com maior velocidade do que as grandes, diminuindo assim seu período de exposição às condições potencialmente estressantes nesse ambiente (Simão Neto et al. 1987).

Considerando-se o potencial do gado bovino em dispersar, por longas distâncias, grandes quantidades de sementes de muitas espécies (Janzen 1984; Fischer et al. 1996), e considerando-se que a efetividade da dispersão depende, entre outros aspectos, da quantidade de sementes íntegras dispersadas e qualidade fisiológica, a qual pode ser avaliada por intermédio de variáveis como a capacidade e velocidade de germinação (Gordon 1973), o principal objetivo deste trabalho foi avaliar a recuperação e qualidade fisiológica de sementes de Leucaena leucocephala, Cajanus cajan e Calopogonium mucunoides após passagem pelo trato digestório de Bos taurus Linnaeus (1758). A hipótese a ser testada é a de que o gado bovino constitua-se num dispersor legítimo dessas espécies, que estão entre as leguminosas mais utilizadas como forragem para bovinos no Brasil (Pereira 2009).

\section{Material e Métodos}

\section{Material vegetal}

Os ensaios foram realizados com sementes de Leucaena leucocephala (Lam.) de Wit (Mimosaceae) (leucena), cultivar cunningham, Cajanus cajan (L.) Huth (Fabaceae) (feijão-guandú), cultivares fava larga e anão, e Calopogonium mucunoides Desv. (Fabaceae) (calopogônio). Leucena é uma árvore originária da
América Central e amplamente distribuída pelos continentes (Castro \& Dutra 1997), sendo considerada espécie exótica invasora do território brasileiro (Instituto Hórus de Desenvolvimento e Conservação Ambiental \& The Nature Conservancy 2008). Suas sementes possuem em média $8,4 \mathrm{~mm}$ de comprimento, $6 \mathrm{~mm}$ de largura e 1,8 mm de espessura (Gardener et al. 1993a), com elevada porcentagem (83\%) de dormência tegumentar (Oliveira \& Medeiros Filho 2007, Serrato-Valenti et al. 1994). Feijão-guandú é um arbusto originário da Índia ou Austrália, sendo muito usado no Brasil como planta forrageira. Apresenta sementes com comprimento médio de 5,9, 5,8 $\mathrm{mm}$ de largura e $5 \mathrm{~mm}$ de espessura, cujo tegumento é considerado "mole" (Gardener et al. 1993a). Calopogônio, originário da América Central, é uma planta perene com hábito de crescimento rasteiro e trepador, cujas sementes podem apresentar dormência tegumentar (Deminicis et al. 2006).

As sementes utilizadas no trabalho foram adquiridas junto à empresa PRÓSEMENTES, Araçatuba, SP, em novembro de 2007, tendo sido colhidas no período de março a setembro de 2007. As sementes apresentaram teores de água similares, variando de aproximadamente $11,5 \%$ (Cajanus cajan e Calopogonium mucunoides) até 8,6\% (Leucaena leucocephala). As sementes de C. cajan e C. mucunoides apresentam formato arredondado, enquanto que Leucaena é achatada. Quanto ao tamanho, as menores sementes foram as de C. mucunoides (3,3 $\pm 0,02 \mathrm{~mm}$ de comprimento), e as maiores aquelas de L. leucocephala $(8,9 \pm 0,07 \mathrm{~mm})$. As sementes de C. mucunoides foram as que apresentaram a menor massa de matéria fresca $(0,012 \mathrm{~g})$, enquanto que $C$. cajan cv. fava larga apresentou a maior $(0,115 \mathrm{~g})$. Com exceção de L. leucocephala, cuja porcentagem de germinação das sementes intactas ficou em torno de $40 \%$, as demais sementes apresentaram porcentagens de germinação acima de $80 \%$. Testes de imersão em água destilada mostraram que as sementes de $C$. cajan cv. fava larga e anão, e C. mucunoides apresentaram um ganho de aproximadamente $100 \%$ da massa fresca devido à entrada de água (embebição) nas primeiras 10 horas, ao passo que as sementes de L. leucocephala apresentaram uma hidratação em torno de $29 \%$ ao final de 26 horas.

\section{Oferta das sementes aos animais}

Os trabalhos envolvendo o oferecimento de sementes aos animais, coleta e triagem do material foram realizados no sítio Boa Esperança, localizado no Km 7 da Rodovia SP-221 (21 13' 5.54” S e $49^{\circ} 00^{\prime} 31.52^{\prime}$ O), Município de Catanduva, SP, durante os meses de janeiro e fevereiro de 2008. Para cada leguminosa, 9.000 sementes foram misturadas a um composto de $10 \mathrm{~kg}$ de capimnapier (Pennisetum purpureum Schumach cv. napier) triturado e $3 \mathrm{~kg}$ de farelo de arroz (Oryza sativa L.). A mistura foi distribuída equitativamente a três fêmeas da espécie Bos taurus às 06:00. Às 18:00 do mesmo dia (12 horas após a oferta das sementes) as fezes desses animais começaram a ser recolhidas, estendendo-se a coleta até as 18:00 do dia seguinte, ou seja, 36 horas após a oferta. Este período foi estabelecido baseado em ensaios preliminares onde se verificou queda drástica na quantidade de sementes eliminadas nas fezes após 36 horas da ingestão.

Previamente à oferta das sementes aos animais, os mesmos foram alimentados por 24 horas com capim-napier triturado e farelo de arroz, sem restrições quanto à quantidade, a fim de eliminar sementes pré-ingeridas do trato digestório. As sementes não ingeridas foram contadas e descontadas do valor inicial de 9.000 sementes fornecidas aos animais.

\section{Recuperação das sementes das fezes}

Fezes contendo as sementes foram amolecidas em água, em balde de $20 \mathrm{~L}$, e passadas em peneiras de diferentes crivos $(4 \times 4$; $2,5 \times 2,5 \mathrm{ou} ; 1 \times 1 \mathrm{~mm})$, conforme o tamanho da semente. O material 
retido nas peneiras foi submetido à inspeção visual, sendo as sementes removidas com auxílio de pinça e colocadas para secar à sombra por 36 horas. Em seguida, as sementes foram contadas, avaliadas quanto à integridade morfológica e acondicionadas em envelopes de papel, sendo transportadas para o laboratório onde foram realizados os ensaios de germinação.

\section{Ensaios de germinação com sementes recuperadas das fezes}

Todos os testes foram realizados no Departamento de Botânica do Instituto de Biociências da UNESP de Rio Claro, São Paulo. Foram realizados dois ensaios de germinação, sendo um em condições controladas e outro em condições não controladas (Casa de Vegetação). $\mathrm{O}$ experimento em condições controladas foi realizado em caixas de germinação (gerbox) de $115 \times 115 \times 35 \mathrm{~mm}$, com cinco repetições por espécie/variedade e 50 sementes por repetição. Os testes foram realizados em sala climatizada, à temperatura de $26 \pm 2{ }^{\circ} \mathrm{C}$, sob luz branca contínua com irradiância de aproximadamente $27 \mu \mathrm{mol} . \mathrm{s}^{-1} \cdot \mathrm{m}^{-2}$. A protrusão radicular foi usada como critério de germinação. Inspeções foram realizadas diariamente até cessarem as germinações. Para os ensaios, as sementes não sofreram qualquer tipo de escarificação. Foram utilizados dois tipos de substrato: papel filtro; e as próprias fezes dos animais. Como controle, foram usadas sementes que não passaram pelo trato digestório dos animais. As variáveis observadas foram a porcentagem de Germinação $(\mathrm{G})$ e a velocidade média de germinação $(\mathrm{V})$, avaliada de acordo com a fórmula: $\mathrm{V}=\Sigma \mathrm{n}_{\mathrm{i}} / \Sigma\left(\mathrm{n}_{\mathrm{i}} \cdot \mathrm{t}_{\mathrm{i}}\right)$, onde $n_{\mathrm{i}}$ é o número de sementes germinadas no intervalo de tempo $\mathrm{t}_{\mathrm{i}}$ (Labouriau 1983).

No ensaio de germinação sobre as próprias fezes do animal, uma parte das fezes contendo as sementes foi recolhida, homogeneizada e colocada para secar por 96 horas em condições naturais, sobre sacos de estopa. A amostra foi então dividida em oito partes contendo $250 \mathrm{~mL}$ de material cada, as quais foram espalhadas dentro de oito bandejas de papel aluminizado com fundo perfurado, medindo $16 \times 10,5 \times 3,5 \mathrm{~cm}$ e com capacidade de $500 \mathrm{~mL}$, contendo uma camada de $1,5 \mathrm{~cm}$ de espessura de areia fina esterilizada (volume de $250 \mathrm{~mL}$ ). A estimativa da quantidade de sementes presentes em cada bandeja foi feita por intermédio da determinação prévia de sementes presentes em 5 amostras de $250 \mathrm{~mL}$ do substrato utilizado para o preenchimento da bandeja. As contagens do número de plântulas emergidas foram realizadas diariamente, usando-se como critério de germinação a expansão do primeiro par de folíolos. O acompanhamento da germinação foi interrompido ao $34^{\circ}$ dia, quando todas as sementes não germinadas já haviam se deteriorado.

O ensaio em condições não controladas foi realizado em Casa de Vegetação, entre março e abril de 2008, com temperatura variando de 16 a $36{ }^{\circ} \mathrm{C}$ no período do experimento e irradiância média de $116 \mu \mathrm{mol} . \mathrm{m}^{-2} . \mathrm{s}^{-1}$ (radiação fotossinteticamente ativa). Teve o objetivo de avaliar possível mudança no vigor das sementes através do Índice de Velocidade de Emergência (IVE), onde se utilizou como substrato uma mistura de areia, vermiculita e Plantmax ${ }^{\circledR}$ (1:1:1) O índice de velocidade de emergência foi calculado de acordo com a fórmula: (Maguire 1962) IVE $=\Sigma\left(n_{i} / t_{i}\right)$, onde $n_{i}$ é o número de plântulas emergidas no intervalo $t_{i}$.

As sementes foram semeadas de maneira equispaçada em bandejas de papel aluminizado conforme descrito acima e enterradas a $1 \mathrm{~cm}$ da superfície. Em cada bandeja foram colocadas seis sementes, sendo oito bandejas com sementes tratadas (recuperadas) e oito com sementes não tratadas (in natura) para cada espécie/variedade. $\mathrm{O}$ experimento foi acompanhado por um período de 21 dias desde a semeadura. $\mathrm{O}$ critério de emergência foi a expansão do primeiro par de folíolos. Todos os ensaios permaneceram sob irrigação diária, de modo a manter o substrato constantemente saturado de umidade.

\section{Ensaio de crescimento da plântula a partir de sementes recuperadas das fezes}

Para avaliar possível mudança no padrão de crescimento das plantas cujas sementes passaram pelo trato digestório do animal, em junho de 2008, sementes de cada espécie/cultivar foram primeiramente colocadas para germinar sob as mesmas condições descritas anteriormente. As sementes de Leucaena leucocephala foram escarificadas com lixa $n .^{\circ} 100$ por aproximadamente 10 segundos para facilitar a embebição das sementes. As sementes germinadas (protrusão radicular e curvatura geotrópica da radícula) foram transferidas para bandejas aluminizadas com fundo perfurado, preenchidas com uma mistura de areia, vermiculita e Plantmax ${ }^{\circledR}$ (1:1:1), e colocadas em Casa de Vegetação. Em cada bandeja foram colocadas seis plântulas distribuídas de maneira equispaçada, sendo oito bandejas com plântulas originadas de sementes tratadas (recuperadas) e oito bandejas com plântulas originadas de sementes não tratadas (in natura) de cada espécie/variedade. O experimento foi acompanhado durante 24 dias desde a semeadura. A altura da planta foi medida diariamente com auxílio de régua graduada, considerandose altura a distância entre o colo da planta (superfície do substrato) e o ápice caulinar. O substrato foi mantido permanentemente à capacidade de campo.

\section{Análise dos dados}

O experimento seguiu um delineamento inteiramente ao acaso (Vieira 1999). Os dados obtidos dos ensaios de germinação foram submetidos a teste de normalidade e homogeneidade de variância, seguido por testes de análise de variância ( $t$ de Student) para comparação de médias (controle vs. tratamento), $\operatorname{com} \alpha=0,05$. Valores expressos em porcentagem foram transformados em arcoseno $(\operatorname{arcsen} \sqrt{ } \%)$ antes das análises (Santana \& Ranal 2004). Para o ensaio de crescimento, a análise de variância entre as alturas médias das plantas foi calculada através de teste de comparação das retas $(\alpha=0,05)$, obtidas plotando-se a altura contra o tempo.

\section{Resultados}

\section{Recuperação das sementes das fezes}

As porcentagens de recuperação de sementes aparentemente íntegras variaram de aproximadamente $12 \%$ (fava larga) até cerca de $17,5 \%$ (Calopogonium mucunoides) (Figura 1). A quantidade de sementes danificadas recuperadas nas fezes dos animais foi relativamente baixa (entre 0,3 e 1,3\%) para Cajanus cajan e Leucaena leucocephala, elevando-se para aproximadamente $9 \% \mathrm{em}$ C. mucunoides (Figura 1).

\section{Germinação das sementes recuperadas das fezes}

A passagem das sementes de Cajanus cajan (ambas as cultivares) pelo trato digestório de bovinos reduziu drasticamente sua porcentagem de germinação $(\mathrm{p}=0,000)$, que foi praticamente nula para a cv. Anão (Figura 2a). No caso de Calopogonium mucunoides, a passagem da semente pelo trato digestório causou uma redução da ordem de $17 \%$ na porcentagem de germinação em relação ao grupo controle ( $\mathrm{p}=0,006)$, enquanto que em Leucena leucocephala não houve diferença significativa entre as porcentagens de germinação do controle e tratamento $(\mathrm{p}=0,498)$. Quanto às velocidades médias de germinação (V), em C. cajan cv. anão não foi possível a comparação estatística entre controle e tratamento, pois apenas uma réplica das sementes que passaram pelo trato digestório apresentou germinação, ao passo que na cultivar fava larga não houve efeito significativo do tratamento $(\mathrm{p}=0,605)$ (Figura $2 \mathrm{~b}$ ). Já em C. mucunoides e 


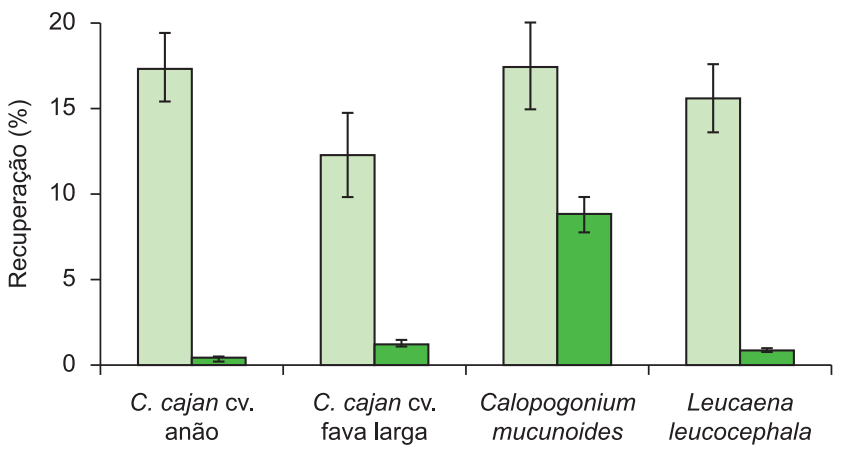

Figura 1. Recuperação de sementes íntegras (verde claro) e danificadas (verde escuro) de Cajanus cajan cv. anão, Cajanus cajan cv. fava larga, Calopogonium mucunoides e Leucaena leucocephala cv. cunningham em fezes de gado bovino, durante 36 horas após ingestão. As barras verticais indicam o intervalo de confiança $(\alpha=95 \%)$, segundo Clopper \& Pearson (1934 apud Labouriau 1983).

Figure 1. Recovery of whole (light green) and damaged (dark green) seeds of Cajanus cajan cv. anão, C. cajan cv. fava larga, Calopogonium mucunoides and Leucaena leucocephala cv. cunningham in cattle's faeces, up to 36 hours from the ingestion. Vertical bars are the confidence interval $(\alpha=95 \%)$ according to Clopper \& Pearson (1934 apud Labouriau 1983).
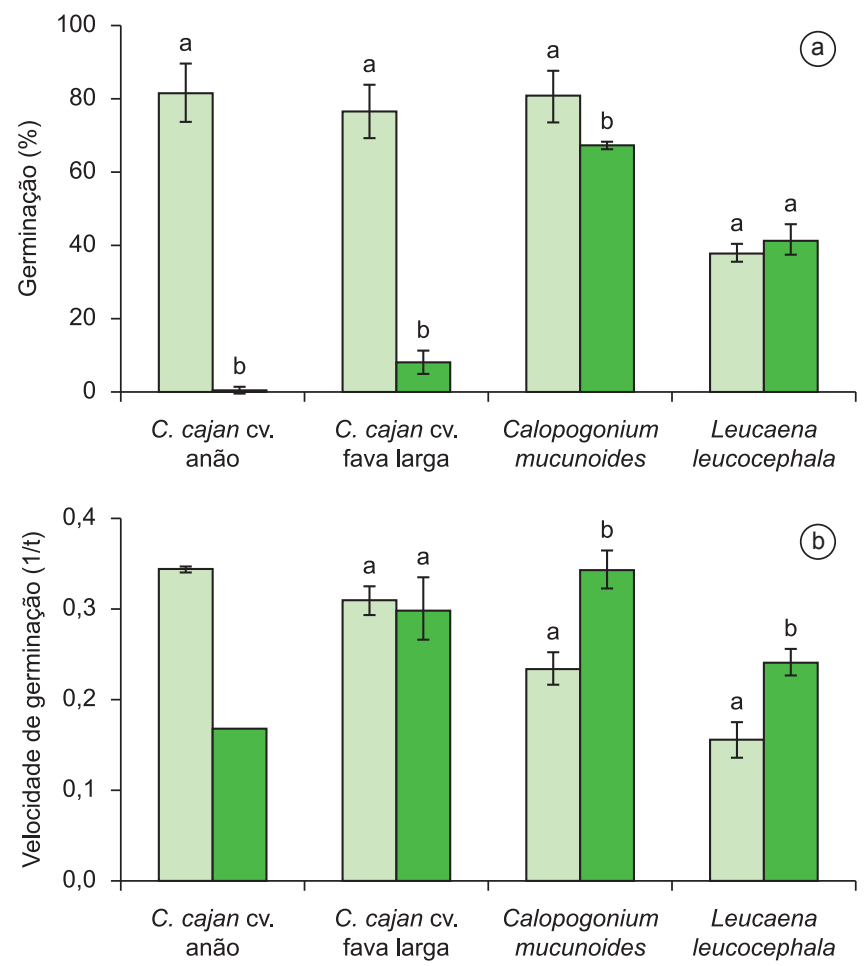

Figura 2. a) Porcentagem e b) velocidade média de germinação de sementes de Cajanus cajan cv. anão, Cajanus cajan cv. fava larga, Calopogonium mucunoides e Leucaena leucocephala cv. cunningham in natura (verde claro) e após passagem pelo trato digestório animal (verde escuro). Dados após 16 dias em sala climatizada, à temperatura de $26 \pm 2{ }^{\circ} \mathrm{C}$, sob luz branca contínua. As barras verticais indicam o desvio padrão da média. Letras minúsculas comparam sementes tratadas e não tratadas (controle) (teste $t$ de Student, $\alpha=5 \%)$.

Figure 2. a) Germination percentage and b) germination rate of Cajanus cajan cv. anão, C. cajan cv. fava larga, Calopogonium mucunoides and Leucaena leucocephala cv. cunningham seeds in natura (light green) and after passage through cattle's digestive system (dark green). Data after 16 days at $26 \pm 2{ }^{\circ} \mathrm{C}$, under continuous white light. Vertical bars indicate the standard deviation of the mean. Small letters compare treated and non-treated seeds (Student's $t$ test; $\alpha=5 \%$ ).
L. leucocephala, o tratamento causou um acréscimo significativo em V (p = 0,000) (Figura 2b). No ensaio de germinação utilizando como substrato as próprias fezes dos animais, a germinação de sementes de $C$. cajan cv. anão foi nula, enquanto que as sementes de $C$. cajan cv. fava larga e C. mucunoides, apesar de apresentarem protrusão radicular, não produziram plântulas com expansão do primeiro par de folíolos - critério utilizado para definir uma semente germinada - apresentando sinais de murcha e posterior morte. Em L. leucocephala, aproximadamente $10 \%$ das plântulas apresentaram folíolos expandidos, os quais, entretanto, apresentaram-se tortuosos e quebradiços, com manchas avermelhadas (E.A. Nakao \& V.J.M. Cardoso, dados não publicados).

No ensaio de Casa de Vegetação, o Índice de Velocidade de Emergência (IVE) de sementes de Calopogonium mucunoides $(p=0,023)$ decresceu significativamente em decorrência da passagem pelo trato digestório, sendo que no caso de $C$. cajan cv. anão a germinação das sementes tratadas foi nula, não sendo possível o cálculo do respectivo IVE (Figura 3). Em Leucaena leucocephala ( $\mathrm{p}=0,052)$ e Cajanus cajan $\mathrm{cv}$. fava larga $(\mathrm{p}=0,095)$, por sua vez, os IVE do tratamento e do controle não diferiram significativamente entre si (Figura 3).

\section{Crescimento a partir de sementes recuperadas das fezes}

A passagem de sementes de Cajanus cajan cv. fava larga pelo trato digestório dos bovinos causou uma redução na taxa de crescimento em altura das plântulas $(T=18,9-$ Tcrítico $=2.048)($ Figura 4a), efeito esse que foi bem menos acentuado no caso de Calopogonium mucunoides $(\mathrm{T}=4,18$ - Tcrítico $=2.048)($ Figura 4b). Em Leucaena leucocephala, a altura foi maior em plântulas originadas de sementes tratadas em comparação com o controle, embora as respectivas taxas de crescimento (variação da altura em função do tempo) tenham sido similares $(\mathrm{T}=1,38-\mathrm{Tc}$ í́tico $=2.048)$ (Figura 4c). Não foram apresentados os resultados de $C$. cajan cv. anão, uma vez que as sementes tratadas não germinaram.

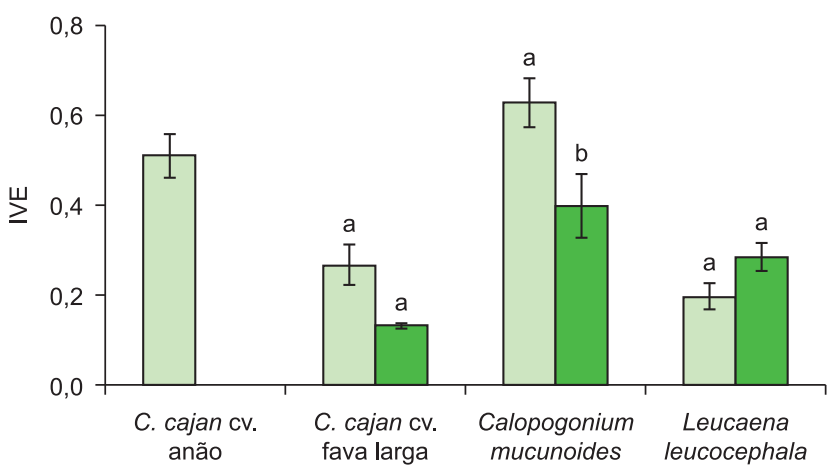

Figura 3. Índice de velocidade de emergência de sementes de Cajanus cajan cv. anão, Cajanus cajan cv. fava larga, Calopogonium mucunoides e Leucaena leucocephala $\mathrm{cv}$. cunningham in natura (verde claro) e após passagem pelo trato digestório animal (verde escuro). As barras verticais indicam o desvio padrão das médias. Letras minúsculas comparam sementes tratadas e não tratadas (controle) (teste $t$ de Student, $\alpha=5 \%$ ).

Figure 3. Emergence rate index of Cajanus cajan cv. anão, Cajanus cajan cv. fava larga, Calopogonium mucunoides and Leucaena leucocephala cv. cunningham seeds in natura (light green) and after passage through cattle's digestive system (dark green). The vertical bars indicate the standard deviation of the means. Small letters compare treated and non-treated seeds (Student's $t$ test; $\alpha=5 \%$ ). 

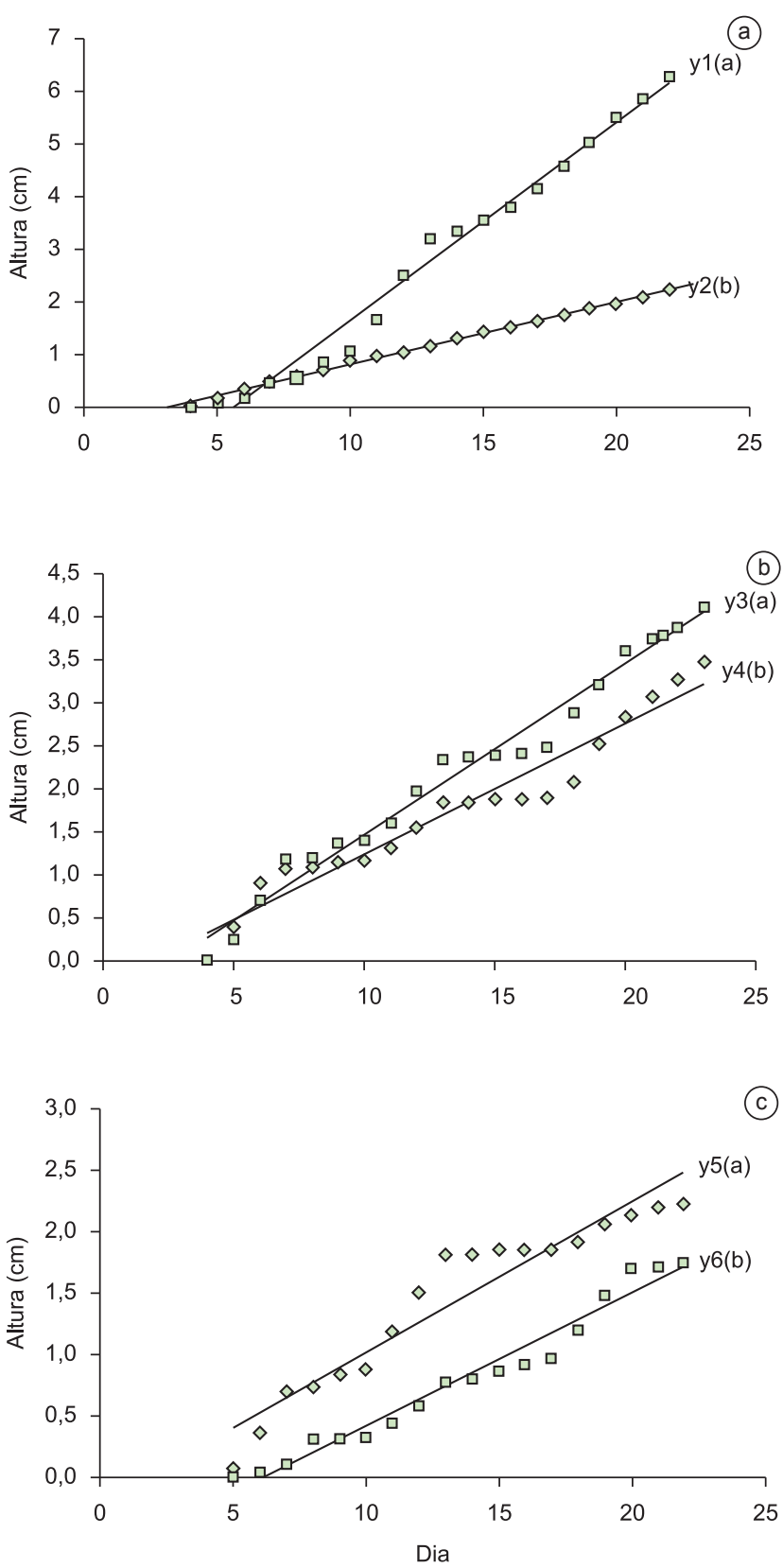

Figura 4. Curvas de crescimento em altura de plântulas de Cajanus cajan cv. fava larga (a), Calopogonium mucunoides (b) e Leucaena leucocephala cv. cunningham (c) de sementes in natura ( $\square$ ) e após passagem pelo trato digestório animal $(\diamond)$. Linhas representam ajuste por polinômio de $1^{\mathrm{a}}$ ordem, descritas pelas seguintes equações: $y 1=0,375 x-2,0989\left(R^{2}=0,9816\right)$; y2 $=0,1187 x-0,3604\left(R^{2}=0,997\right) ; y 3=0,1992 x-0,5271\left(R^{2}=0,9762\right)$; $y 4=0,1523 x-0,9471\left(R^{2}=0,9471\right) ; y 5=0,1219 x-0,2081\left(R^{2}=0,9139\right)$; y6 $=0,1072 \mathrm{x}-0,6581\left(\mathrm{R}^{2}=0,9663\right)$. Letras minúsculas comparam as inclinações das curvas para cada espécie (Teste $t$ de Student).

Figure 4. Time courses of the growth in height of Cajanus cajan cv. fava larga (A), Calopogonium mucunoides (B) and Leucaena leucocephala cv. cunningham $(C)$ seedlings from non-treated $(\square)$ and after passage through cattle's digestive system $(\diamond)$ seeds. Points were fitted by linear models described by the following equations: $y 1=0,375 x-2,0989\left(R^{2}=0,9816\right)$; $\mathrm{y} 2=0,1187 \mathrm{x}-0,3604\left(\mathrm{R}^{2}=0,997\right) ; \mathrm{y} 3=0,1992 \mathrm{x}-0,5271\left(\mathrm{R}^{2}=0,9762\right)$; $\mathrm{y} 4=0,1523 \mathrm{x}-0,9471\left(\mathrm{R}^{2}=0,9471\right) ; \mathrm{y} 5=0,1219 \mathrm{x}-0,2081\left(\mathrm{R}^{2}=0,9139\right)$ y6 $=0,1072 x-0,6581\left(R^{2}=0,9663\right)$. Small letters compare the slopes of the curves for each species (Student's $t$ test).

\section{Discussão}

Em relação ao total de sementes fornecidas aos animais, as baixas porcentagens de recuperação de sementes nas fezes sugerem que as três espécies sofreram igualmente os danos causados pela ingestão e passagem pelo trato digestório das vacas, independentemente do tamanho da semente, contrariando as conclusões de Simão Neto et al. (1987). Para estes autores, sementes grandes são mais propensas a danos causados pela mastigação, já que uma pequena fissura no tegumento da semente é suficiente para expô-las ao ataque de substâncias e microorganismos presentes no suco gástrico. Esses autores sugerem também que sementes com tegumento duro resistem melhor aos danos causados pela pressão dos dentes durante a mastigação do que sementes com tegumento mole. Entretanto, esse fato não pode ser demonstrado no presente trabalho, considerandose que as sementes de leucena, com base nos testes de embebição, revelaram-se mais "duras" do que as demais, mas apresentaram porcentagens de recuperação similares.

A passagem pelo trato digestório de Bos taurus afetou severamente a capacidade de germinação das sementes de ambas as variedades de Cajanus cajan, o que reforça as observações de Gardener et al. (1993a), segundo as quais sementes dessa espécie, ao atravessarem o trato digestório de bovinos, dilatam-se em consequência da embebição e apresentam rompimento da testa. Assim, a baixa porcentagem de germinação de sementes tratadas de $C$. cajan poderia estar relacionada a um "amolecimento" da semente causado pela sua hidratação no interior do trato digestório, o que levaria à perda de viabilidade da semente em decorrência da ação do suco gástrico (Gardener et al. 1993a, b). Vale destacar que, diferentemente dos ensaios realizados no presente estudo, esses autores introduziam e retiravam as sementes do rúmen (após 48 horas) por intermédio de fístulas. Para as sementes de Calopogonium mucunoides, a passagem pelo trato digestório também reduziu a porcentagem de germinação, mas numa escala bem menor do que a observada em C. cajan. Essa pequena redução pode estar associada a diferentes fatores, associados às condições potencialmente estressantes encontradas no trato digestório bovino. Tais condições poderiam simular tratamentos que causam o chamado "envelhecimento artificial" da semente, obtido em ambientes com alta temperatura e umidade relativa do ar, causando uma menor porcentagem de germinação e vigor, como demonstrado em sementes de Copaifera langsdorffii Desf. (Ferreira et al. 2004). No caso de Leucena leucocephala, assim como observado por Gardener et al. (1993a), a capacidade de germinação não foi influenciada pelo tratamento, o que no caso pode estar relacionado a uma maior dureza do tegumento em pelo menos uma parcela da população de sementes. Em outras palavras, as sementes que "sobreviveram" à passagem pelo trato digestório e foram recuperadas nas fezes devem apresentar tegumentos mais resistentes às condições do meio do que as demais. No caso de C. cajan, as poucas sementes tratadas que germinaram o fizeram numa velocidade igual àquela de sementes do grupo controle, enquanto que as sementes de C. mucunoides e L. leucocephala que passaram pelo trato digestório germinaram mais rapidamente do que as não tratadas, resultado que pode estar relacionado a um efeito "priming" (osmocondicionamento). No osmocondicionamento, a semente é submetida a uma hidratação prévia controlada, geralmente numa solução osmótica, seguida de secagem. Quando a semente é colocada finalmente para germinar, a velocidade do processo tende a ser maior, tendo em vista que algumas etapas do metabolismo germinativo já foram cumpridas durante o "priming" (Castro \& Hilhorst 2004, Nascimento 1998, Heydecker et al. 1973). Assim, sugere-se que sementes de C. mucunoides e L. leucocephala possam ter apresentado alguma hidratação durante sua passagem pelo trato digestório, seguida de uma secagem entre as etapas de triagem das 
fezes e início dos testes de germinação. No caso de Cajanus cajan, por outro lado, essa possível hidratação prévia das sementes nas condições do trato digestório bovino provavelmente não foi suficiente para produzir um efeito "priming" e, portanto, alterar a velocidade da germinação. O maior tempo de permanência no trato digestório das sementes de C. mucunoides e L. leucocephala em comparação com C. cajan (E.A. Nakao \& V.J.M. Cardoso, dados não apresentados) também pode ter contribuído para os resultados de velocidade. Por outro lado, no caso de $C$. mucunoides, a resposta ao tratamento foi diferente quando se usou o IVE como parâmetro, o qual foi reduzido nas sementes tratadas, sugerindo que o crescimento inicial, correspondente ao estádio de emergência do hipocótilo e expansão dos eófilos, foi influenciado negativamente pela passagem através do trato digestório bovino, o que mostra uma redução no vigor da plântula. Essa redução não ocorreu em sementes de leucena, o que se assemelha à resposta de algumas gramíneas cuja velocidade de germinação (protrusão radicular), após passagem pelo trato digestório de ovelhas, foi reduzida apenas nas sementes "moles", enquanto que aquelas com tegumento "duro" (impermeável) não foram afetadas (Peco et al. 2006). Assim como a germinação, o crescimento inicial das plântulas também foi influenciado negativamente pela passagem através do trato digestório, particularmente no caso de $C$. cajan, cujo tegumento, a exemplo de $C$. mucunoides, é considerado menos resistente em comparação o de sementes de leucena (Gardener et al. 1993a).

Os resultados aqui obtidos sugerem também que as próprias fezes bovinas não devem constituir um meio favorável ao crescimento inicial da plântula, tendo em vista a germinação baixa ou nula, bem como a morfologia da plântula de Cajanus cajan cv. fava larga, Calopogonium mucunoides e Leucaena leucocephala nesse substrato, o qual pode ter se revelado tóxico às plântulas, principalmente devido a possíveis variações do $\mathrm{pH}$ e compostos nitrogenados causadas por atividade microbiana (Braz et al. 2002). Segundo Janzen (1984), o tempo de permanência das sementes em fezes tem relação direta com a mortalidade das sementes. Por outro lado, ao contrário do que ocorre em condições de laboratório, onde os fatores temperatura, luz e água permanecem relativamente estáveis ao longo de todo o experimento, no campo, dependendo das condições ambientais, em dois dias uma placa de fezes torna-se totalmente seca, diminuindo a densidade e atividade de microorganismos decompositores (Braz et al. 2002). Além disso, o pisoteio, a chuva e, principalmente, a ação de besouros coprófagos podem modificar o substrato e criar um micro-ambiente favorável, ou pelo menos não estressante, à germinação e crescimento das plântulas de C. cajan, C. mucunoides e L. leucocephala depositadas nas fezes, de modo que essas não venham a atuar como fator limitante da dispersão. Em relação à germinação, sementes de L. leucocephala passadas pelo trato digestório mostraram-se menos susceptíveis à ação do meio constituído pelas fezes bovinas, embora a porcentagem de germinação (10\%) tenha sido baixa em comparação com os resultados obtidos por Gardener (1993), que mostram uma germinação de quase $50 \%$, após 29 dias, de sementes de leucena em fezes bovinas mantidas em condições ambientais não controladas.

Considerando os resultados de recuperação de sementes em fezes, germinação e crescimento inicial das plântulas, o gado bovino não pode ser considerado um legítimo dispersor para Leucaena leucocephala, Calopogonium mucunoides e Cajanus cajan, refutando a hipótese inicial deste trabalho. Entretanto, isso não significa que o gado não possa atuar como dispersor de L. leucocephala $\mathrm{e}$, em menor escala, de $C$. mucunoides, considerando-se a dureza (impermeabilidade) do tegumento das sementes, no caso da primeira, e o tamanho relativamente pequeno das mesmas, no caso da segunda. Dessa forma, a ação do gado poderia contribuir para a redução dos custos de ressemeadura de leucena e calopogônio para o produtor.
Indiretamente, os resultados alertam para possíveis impactos ambientais decorrentes da invasão do gado em áreas de conservação de biodiversidade, já que os mesmos podem atuar como potenciais agentes disseminadores de espécies alóctones. Ressalta-se ainda a necessidade de novos experimentos para se testar a eficiência e efetividade da dispersão de sementes dessas espécies por bovinos em condições de campo.

\section{Referências Bibliográficas}

BRAZ, S.P., NASCIMENTO, J.R.D. \& CANTARUTTI, R.B. 2002. Aspectos quantitativos de reciclagem de nutrientes pelas fezes de bovinos sob pastejo em pastagem de Brachiaria decumbens na Zona da Mata de Minas Gerais. Rev. Bras. Zoot. 31(2):858-865.

CASTRO, J.R. \& DUTRA, A.S. 1997. Influência do tamanho das sementes de Leucena (Leucaena leucocephala (Lam.) De Wit) cv. cunningham na germinação e no vigor. Rev. Bras. Sementes. 19(1):88-90.

CASTRO, R.D. \& HILHORST, H.W.M. 2004. Embebição e reativação do metabolismo. In Germinação: do básico ao aplicado (Ferreira, A.G. \& Borguetti, F., Org.). Artmed, Porto Alegre.

DEMINICIS, B.B., ALMEIDA, J.C.C., BLUME, M.C., ARAÚJO, S.A.C., PÁDUA, F.T., ZANINE, A.M. \& JACCOUD, C.F. 2006. Superação da dormência de sementes de oito leguminosas forrageiras tropicais. Arch. Zootec. 55(212):401-404.

FERREIRA, R.A., OLIVEIRA, L.M., CARVALHO, D., OLIVEIRA, A.F. \& GEMAQUE, R.C.R. 2004. Qualidade fisiológica de sementes de Copaifera langsdorffii Desf. (Leguminosae Caesalpinioideae) envelhecidas artificialmente. Rev. Ciênc. Agron. 35(1):82-86.

FIGUEROA, J.A. \& CASTRO S.A. 2002. Effects of bird ingestion on seed germination of four woody species of the temperate rainforest of Chiloé island. Plant Ecol. 160:17-23.

FISCHER, S.F., POSCHLOD, P. \& BEINLICH, B. 1996. Experimental studies on the dispersal of plants and animals on sheep in calcareous grasslands. J. Appl. Ecol. 33:1206-1222.

FLEMING, T.H. \& SOSA, V.J. 1994. Effects of nectarivorous and frugivorous mammals on reproductive success of plants. J. Mammal. 75(4):845-851.

GARDENER, C.J. 1993. The colonization of a tropical grassland by Stylosanthes from seed transported in cattle faeces. Austr. J. Agric. Res. 44:299-315.

GARDENER, C.J., McIVOR, J.G. \& JANSEN, A. 1993a. Passage of legume and grass seeds through the digestive tract of cattle and their survival in faeces. J. Appl. Ecol. 30(1):63-74.

GARDENER, C.J., McIVOR, J.G. \& JANSEN, A. 1993b. Survival of seeds of tropical grasslands species subjected to bovine digestion. J. Appl. Ecol. 30(1):75-85.

GÖKBULAK, F. \& CALL, C. 2004. Grass seedlingrecruitment in cattle dungpats. J. Range Management, 57(6): 649-655.

GORDON, A.G. 1973. The rate of germination. In Seed Ecology (Heydecker, W., Ed.). Butterworths, Londres, p.391-410.

HEYDECKER, W., HIGGIS, J. \& GULLIVER, R.L. 1973. Accelerated germination by osmotic treatment. Nature 246:42-44.

INSTITUTO HÓRUS DE DESENVOLVIMENTO E CONSERVAÇÃO AMBIENTAL \& THE NATURE CONSERVANCY. 2008. Espécies exóticas invasoras: fichas técnicas. http://www.institutohorus.org.br/ inf_fichas.htm (último acesso em 12/03/2009).

JANZEN, D.H. 1970. Herbivores and the number of tree species in tropical forests. Am. Nat. 104:501-528.

JANZEN, D.H. 1984. Dispersal of small seeds by big herbivores: foliage is the fruit. Am. Nat. 123:338-353.

JANZEN, D.H. 1985. How fast and why do germinating guanacaste seeds (Enterolobium cyclocarpum) die inside cows and horse. Biotropica 17(4):322-325.

LABOURIAU, L.G. 1983. A germinação das sementes. Edições OEA, Washington. 
MACHADO, L.A.Z., DENARDIN, R.N. \& JACQUES, A.V. 1997. A percentagem e dureza do tegumento de sementes de três espécies forrageiras recuperadas em fezes ovina. Rev. Bras. Zootecn. 26(1):42-45.

MAGUIRE, J.D. 1962. Speed of germination - aid in selection and evaluation for seedling emergence and vigor. Crop Science. 2(2):176-177.

MALO, J.E. \& SUÁREZ, F. 1995. Establishment of pasture species on cattle dung: the role of endozoochorous seeds. J. Veg. Sci. 6:169-174.

NASCIMENTO, W.M. 1998. Condicionamento osmótico de sementes de hortaliças: potencialidades e implicações. Hort. Brasil. 16:106-109.

OLIVEIRA, A.B. \& MEDEIROS FILHO, S. 2007. Influência de tratamentos pré-germinativos, temperatura e luminosidade na germinação de sementes de Leucaena leucocephala cv. cunningham. Rev. Bras. Ciênc. Agrár. 2(4):268-274.

PECO, B., LOPEZ-MERINO, L. \& ALVIR, M. 2006. Survival and germination of mediterranean grassland species after simulated sheep ingestion ecological correlates with seed traits. Acta Oecol. 30(2):269-275.

PEREIRA, J.M. 2009. Utilização de leguminosas forrageiras na alimentação de bovinos. http://www.ceplac.gov.br/radar/Artigos/artigo29.htm (último acesso em 05/10/2009).
QUINN, J.A., MOWREY, D.P., EMANUELE, S.M. \& WHALLEY, R.D.B. 1994. The "foliage is the fruit" hypothesis: Buchloe dactyloides (Poaceae) and the shortgrass prairie of North America. Am. J. Bot. 8:1545-1554.

SANTANA, D.G. \& RANAL, M.A. 2004. Análise estatística. In Germinação: do básico ao aplicado (Ferreira, A.G. \& Borguetti, F., Org.). Artmed, Porto Alegre.

SERRATO-VALENTI, G., CORNARA, L., GHISELLINI, P. \& FERRANDO, M. 1994. Testa structure and histochemistry related to water uptake in Leucaena leucocephala Lam. (De Wit). Ann. Bot-London. 73:531-537.

SIMÃO NETO, M., JONES, R.M. \& RATCLII, D. 1987. Recovery of pasture seed ingested by ruminants. 1 . seed of six tropical pasture species fed to cattle, sheep and goats. Aust. J. Exp. Agr. 27(2):239-246.

VIEIRA, S. 1999. Estatística experimental. 2. ed. Editora Atlas, São Paulo.

Recebido em 10/02/2010

Versão reformulada recebida em 25/08/2010

Publicado em 30/08/2010 